\title{
Epigenetic silencing of EphAI expression in colorectal cancer is correlated with poor survival
}

\author{
NI Herath ${ }^{*, 1}$, J Doecke ${ }^{2}$, MD Spanevello', BA Leggett ${ }^{3,4}$ and AW Boyd ${ }^{1,4}$ \\ 'Leukaemia Foundation Research Laboratory, The Queensland Institute of Medical Research, 300 Herston Road, Brisbane, Queensland 4029, Australia; \\ ${ }^{2}$ Cancer and Population Studies, The Queensland Institute of Medical Research, 300 Herston Road, Brisbane, Queensland 4029, Australia; ${ }^{3}$ Conjoint \\ Gastroenterology Laboratory, Clinical Research Centre, Royal Brisbane Hospital Research Foundation, 300 Herston Road, Brisbane, Queensland 4029, \\ Australia; ${ }^{4}$ Department of Medicine, The University of Queensland, Brisbane, Queensland 4029, Australia
}

Aberrant expression of Eph and ephrin proteins has well-established functions in oncogenesis and tumour progression. We describe EphAI expression in 6 colorectal cancer (CRC) cell lines, 18 controls and 125 CRC specimens. In addition, a well-characterised cohort of 53 paired normal colon and CRCs was also assessed. Expression of EphAI mRNA was assessed by quantitative real-time PCR and correlated with protein expression by flow cytometry, immunoprecipitation, western blotting and immunohistochemistry. Significant upregulation (2- to I0-fold) of EphAI was seen in over $50 \%$ of cases $(P=0.005)$ whereas many of the remainder showed downregulation of EphAI. Intriguingly, EphAI over-expression was more prevalent in stage II compared to stage III CRCs $(P=0.02)$. Low EphAI expression significantly correlated with poor survival $(P=0.02)$. Epigenetic silencing appeared to explain the loss of EphAI expression as methylation of the EphAI CpG island strongly correlated with low EphAI expression $(P<0.01)$. Furthermore, EphAI re-expression could be induced by treatment with demethylating agents. Our findings identify EphAI as a potential prognostic marker in CRC. Although therapies targeting high EphAI expression seem plausible in CRC, the loss of expression in advanced disease suggests a potential risk that targeted therapy, by selecting for loss of expression, might contribute to disease progression. British Journal of Cancer (2009) 100, 1095- I 102. doi:I0.1038/sj.bjc.6604970 www.bjcancer.com

Published online 10 March 2009

(c) 2009 Cancer Research UK

Keywords: EphAI; colorectal cancer; methylation; quantitative PCR; downregulation

The 16 vertebrate Eph receptors (EphA1-10, EphB1-6) form the largest subfamily of receptor tyrosine kinases. Activation of signalling by these receptors is mediated by interaction with nine cell-surface counter receptors known as ephrins. Eph receptors are divided into two classes, $\mathrm{A}$ and $\mathrm{B}$, based on structural features of their ligand-binding domains and preferential binding to either ephrins A1-6 or ephrins B1-3 groups, respectively (Boyd and Lackmann, 2001). The ephrin A ligands are bound to the cell surface by a glycosyl phosphatidylinositol anchor and bind to class A receptors, whereas the ephrin $B$ ligands are type I transmembrane proteins and bind to class B receptors (Gale et al, 1996).

Eph-ephrin interactions are known to mediate both proadhesive and anti-adhesive signals in both normal and tumour cells and also have a function in tumour angiogenesis (Adams, 2002; Wilkinson, 2003). High Eph and ephrin expression has been reported in many human cancers including various carcinomas, melanoma, sarcoma, kidney and brain tumours (Dodelet and Pasquale, 2000; Nakamoto and Bergemann, 2002; Brantley-Sieders et al, 2004). EphB and ephrin B proteins have been implicated in both normal and malignant epithelial tissues. Signalling through EphB2/B3 and ephrin B ligands regulates cell sorting in the mature gut epithelium (Batlle et al, 2002; Sancho et al, 2003). Over-

*Correspondence: Dr NI Herath; E-mail: Nirmitha.Herath@qimr.edu.au Received 17 December 2008; revised 5 February 2009; accepted 10 February 2009; published online 10 March 2009 expression of EphB2, EphB4 and ephrin B1 has been described in gastric, colon and breast cancers (Stephenson et al, 2001; Berclaz et al, 2002; Kataoka et al, 2002). Interestingly, over-expression of ephrin B2 in colorectal cancers (CRCs) appears to correlate with increased tumour angiogenesis, unexpectedly resulting in reduced tumour growth as new vessels were malformed (Liu et al, 2002, 2004).

Although the EphA/ephrin A system has also been implicated in epithelial tissue structure and function, there is less data on EphA/ephrin A expression in gut and CRC (Maru et al, 1990; Saito et al, 2004). EphA1, originally isolated as an amplified gene in a carcinoma cell line (Hirai et al, 1987), is preferentially expressed in epithelial cells. Ephrin A1 is the highest affinity binding ligand for EphA1 (Coulthard et al, 2001), although it also binds ephrin A3 and A4 with lower affinity. In mice, EphA1 is expressed in many epithelial tissues including skin, kidney, liver and thymus (Coulthard et al, 2001). Over-expression of human EphA1 has been observed in prostate, gastric and colon carcinomas (Hirai et al, 1987; Maru et al, 1990; Robinson et al, 1996; Kao et al, 2003). More recently, significant downregulation of EphA1 was reported in non-melanoma skin cancers (Hafner et al, 2006).

Despite a few reports of aberrant expression of EphA1 in CRCs, the prevalence of EphA1 expression and its potential prognostic and therapeutic function in CRC has not been examined systematically. We describe the expression of EphA1 in a series of CRC cell lines, clinical CRC samples and a well-characterised cohort of 
paired normal and CRC samples using quantitative real-time PCR. We show significant EphA1 over-expression in CRCs compared to controls. Interestingly, investigation of paired normal and CRC samples revealed significant EphA1 over-expression in locally invasive CRC (stage II) but also downregulation in metastatic CRC (stage III). Further, there is evidence for active selection against expression in metastatic lesions, mediated through epigenetic gene silencing. Intriguingly, low EphA1 expression correlated with shortened survival. The potential consequences of this on colon cancer cell biology are discussed.

\section{MATERIALS AND METHODS}

\section{Cell lines and clinical samples}

Six CRC cell lines (LIM1215, CaCo2, LISP-1, LOVO, HCT116 and HT29) were cultured in RPMI 1640 medium with $10 \%$ fetal bovine serum (FBS). CaCo2 was cultured in Dulbecco's modified medium (Gibco, Mount Waverley, VIC, Australia) with 20\% FBS. Lines were maintained in a $5 \% \mathrm{CO}_{2}$ humidified incubator at $37^{\circ} \mathrm{C}$. A total of 196 colon specimens were assessed in this study, including colon tissue qPCR arrays (OriGene Technologies, Rockville, MD, USA) consisting of $143 \mathrm{cDNA}$ samples and a well-characterised cohort of 53 paired normal and CRC specimens. The qPCR arrays contained cDNA from 18 normal colon, 21 stage I, 40 stage II, 43 stage III and 21 stage IV CRC samples. The median age of the patients was 70 years (range 31-93 years) with a male/female ratio of $73: 70$. The 53 paired tumour and adjacent non-malignant samples were obtained from the Princess Alexandra Hospital tissue bank and the Royal Brisbane Hospital (Brisbane, Australia). Stages II and III were predominant in this cohort with only four stage I and three stage IV cancers (Supplementary Table 1). The median age of the patients was 72 years (range 29-84 years) with a male/female ratio of $28: 25$. Additional clinical details are presented in Supplementary Table 1. All patient samples were obtained after specific informed consent procedures were approved by the institutional ethics committees of the relevant institutions.

\section{RNA extraction and cDNA synthesis}

Total RNA was isolated using the RNeasy Mini kits (Qiagen, Doncaster, VIC, Australia), according to the manufacturer's instructions. RNA quality was assessed by agarose gel electrophoresis. Before cDNA synthesis, samples were treated with RQ1 RNase-free DNase I (Promega, Sydney, NSW, Australia) and first strand cDNA was synthesised by reverse transcription using Superscript III Reverse Transcriptase (Invitrogen, Mount Waverley, VIC, Australia), according to the manufacturer's instructions.

\section{Relative quantitation by real-time PCR}

Protocol for real-time PCR is described in Supplementary methods.

\section{Immunoprecipitation and western analysis}

Protocols for immunoprecipitation and western analysis are described in Supplementary methods.

\section{Immunohistochemistry}

The protocol for immunohistochemistry is described in Supplementary methods.

\section{Methylation analysis}

Sodium bisulfite modification Genomic DNA was subjected to sodium bisulfite modification using the CpGenome DNA modification kit (Chemicon, Sydney, NSW, Australia) to convert the unmethylated cytosines to uracil.

Bisulfite genomic sequencing Methylation status of the $5^{\prime}$-CG-rich region and the EphA1 $\mathrm{CpG}$ island was determined through bisulfite sequencing and melt curve analyses. EphA1 $5^{\prime}$ UTR primers were: $5^{\prime}$-TTTAAGGAGGTGAATTAGGTGA-3' (sense) and $5^{\prime}$-CCATAAC TCCGAACCGAAAC- $3^{\prime}$ (antisense). PCR was conducted in a final volume of $25 \mu \mathrm{l}$ including $1 \times$ PCR buffer, $80 \mathrm{ng}$ of bisulfitemodified DNA, $3 \mathrm{mM} \mathrm{Mg}^{2}$, of each primer, $3.2 \mathrm{mM} \mathrm{dNTP}$ and $2 \mathrm{M}$ betaine. PCR products were generated using a touchdown PCR cycle with annealing temperatures decreasing $0.5^{\circ} \mathrm{C}$ per cycle from 68 to $60^{\circ} \mathrm{C}$.

For the EphA1 CpG island, bisulfite-modified genomic DNA samples were amplified using double nested oligonucleotides (the primer sequences were designed based on the http://www. mdanderson.org/leukemia/methylation/bpcr.html website). These primer sets were specific to modified templates with no CpG sites in their sequences, therefore, both methylated and unmethylated templates were amplified. EphA1 CpG island primers were F1 $5^{\prime}$-GGTGTTGGTTTTTGGGGTTA- $3^{\prime}$ and R $1-5^{\prime}$-AAAATTCCCTCC CCACTCC- $3^{\prime}$. Nested primers were F2 - $5^{\prime}$-GGTTAGGGTTGGTGT TGTTGTT- $3^{\prime}$ and R2 - ${ }^{\prime}$-AAAACCAAAAATAAACCTAACAAT- $3^{\prime}$. PCR was performed in a final volume of $25 \mu \mathrm{l}$ including $80 \mathrm{ng}$ of bisulfite-modified DNA, $10 \times$ buffer, $3 \mathrm{mM} \mathrm{Mg}^{2+}, 0.4 \mu \mathrm{M}$ of each primer, $3.2 \mathrm{~mm} \mathrm{dNTP}$ and $2 \mathrm{M}$ betaine. Initial amplification was carried out using touchdown PCR from 68 to $60^{\circ} \mathrm{C}$. The second round was performed in a final volume of $25 \mu \mathrm{l}$ with $2.5 \mu \mathrm{l}$ of the primary PCR template as described above. PCR was conducted at $95^{\circ} \mathrm{C}$ for $30 \mathrm{~s}, 50^{\circ} \mathrm{C}$ for $30 \mathrm{~s}$ and $72^{\circ} \mathrm{C}$ for $30 \mathrm{~s}$ for 35 cycles followed by a final extension at $72^{\circ} \mathrm{C}$ for $10 \mathrm{~min}$.

Twenty paired normal and CRC samples for the $5^{\prime}$-CG-rich region and 37 paired normal and $\mathrm{CRC}$ samples for the $\mathrm{CpG}$ island were screened through sequencing. PCR products were cloned into the pGEM-T Easy vector (Promega) following agarose gel purification and 10 individual clones were sequenced from each sample. The percentage of methylation was calculated by dividing the number of $\mathrm{CpG}$ sites methylated with the total number of $\mathrm{CpG}$ sites assessed.

In-tube DNA melting profile A total of 21 paired normal and CRC samples were assessed by fluorescence melting curve analysis as described previously (Worm et al, 2001). DNA with no methylation of the target gene and DNA with complete methylation (using Sss1 methyltransferase to methylate all cytosine residues) were used as negative and positive controls, respectively. Of the 21 paired normal and CRC samples, 5 were also subjected to bisulfite sequencing to ensure that the results were comparable.

PCR products were generated using a block thermocycler as described previously. PCR product $(15 \mu \mathrm{l})$ was mixed with $5 \mu \mathrm{l}$ of $\mathrm{H}_{2} \mathrm{O}$ and $10 \mu \mathrm{l}$ of Quantitect SYBR Green PCR Master Mix (Qiagen). DNA melting curves were acquired on the Rotor-Gene 3000 by measuring the fluorescence of SYBR Green I during a linear temperature transition from 70 to $95^{\circ} \mathrm{C}$ with a ramp of $0.5^{\circ} \mathrm{C} \mathrm{s}^{-1}$.

\section{In vitro demethylation and histone deacetylase inhibition}

To assess whether EphA1 expression could be restored, we treated cell lines with a methyltransferase inhibitor with or without a histone deacetylase (HDAC) inhibitor. A total of $4 \times 10^{5}$ cells were plated into Petri dishes and treated with freshly prepared $2 \mu \mathrm{M}$ $5^{\prime}$-aza-2'-deoxycytidine (Sigma, Castle Hill, NSW, Australia) with or without the HDAC inhibitor, suberic bishydroxamate (SBHA) at a final concentration of $30 \mu \mathrm{g} \mathrm{ml}^{-1}$. Cells were treated for periods of 24,48 and $72 \mathrm{~h}$ with media and inhibitors replaced every $24 \mathrm{~h}$. Cells were harvested at approximately $80 \%$ confluence after the completion of the treatments. Quantitative PCR and bisulfite 
sequencing were performed using RNA and DNA, respectively, as described above. Flow cytometry was used to confirm protein expression. All drug assays were performed in duplicate for reproducibility.

\section{Flow cytometry}

The protocol for flow cytometry is described in Supplementary methods.

\section{Statistical analysis}

Quantitative gene expression data from tissue arrays and paired normal and CRC samples were initially analysed using the nonparametric Mann-Whitney U-test and Kruskal-Wallis test. To enable the adjustment for covariates such as age and gender, we transformed expression data into quartiles and analysed using binary logistic regression (response variable: tumour/no tumour). Expression data from paired normal and CRC samples were also analysed using the Kaplan-Meier and Cox proportional hazards methods. Final statistical models were adjusted for patient characteristics such as age, gender, type, site and stage. All statistical analyses were performed using SPSS for Windows version 15.0, and a $P$-value of $<0.05$ was considered statistically significant. Where appropriate, a Bonferroni adjustment was applied to $P$-values.

\section{RESULTS}

\section{EphA1 expression in CRC cell lines}

Quantitative PCR analysis revealed a diversity of EphA1 mRNA expression in CRC cell lines, with lines showing high (LIM1215, LOVO), moderate (CaCo2, HCT116, LISP1) and low expression (HT29) (Figure 1A). Protein expression was examined by immunoprecipitation and western blotting. EphA1 was expressed as a single protein of the expected size $(\sim 120 \mathrm{kDa})$ (Figure 1B) and was shown to correlate well with mRNA expression. The correlation of mRNA with protein expression was further confirmed by analysis of EphA1 protein by flow cytometry (Figure 1C).

\section{EphA1 expression in colon tissue qPCR arrays}

In keeping with the cell line data, heterogeneous EphA1 expression was also observed in CRC samples. Overall, despite this heterogeneity, when the pooled CRC results were compared with normal colon specimens, EphA1 expression was significantly higher in CRCs compared to the controls $(P=0.005)$ (Figure 2). Interestingly, this difference was only apparent in men $(P=0.003)$. Using binary logistic regression to estimate the risk of normal control tissues progressing to a CRC, we identified an approximate twofold rise in risk per quartile increase in EphA1 expression $(P=0.01$, $\mathrm{OR}=1.94, \mathrm{CI}=1.19-3.40$ ).

Although a majority of CRCs showed upregulation of EphA1, a cohort of CRCs also demonstrated downregulation compared to normal colon specimens (Figure 2). No correlations were seen between EphA1 expression, stage, grade or age.

\section{EphA1 expression in CRC clinical samples}

To further examine the heterogeneity of EphA1 expression, we analysed 53 cases in which both normal and CRC tissues had been obtained from each patient. Again, heterogeneous EphA1 expression was observed, with 2- to 10 -fold upregulation compared with paired normal colon in $52 \%$ of tumours. Interestingly, markedly reduced levels of EphA1 expression compared with paired normal colon were observed in $42 \%$ of CRCs. Of these CRCs, 10 cases were more than 5- to 10 -fold downregulated compared to the paired normal control. Intriguingly, EphA1 downregulation was significantly more common in stage III compared to stage II CRCs, most of which over-expressed EphA1 mRNA $(P=0.02)$ (Figure 3$)$. Patients with low EphA1 expressing CRCs had significantly lower survival than those with high EphA1 expressing CRCs after
A

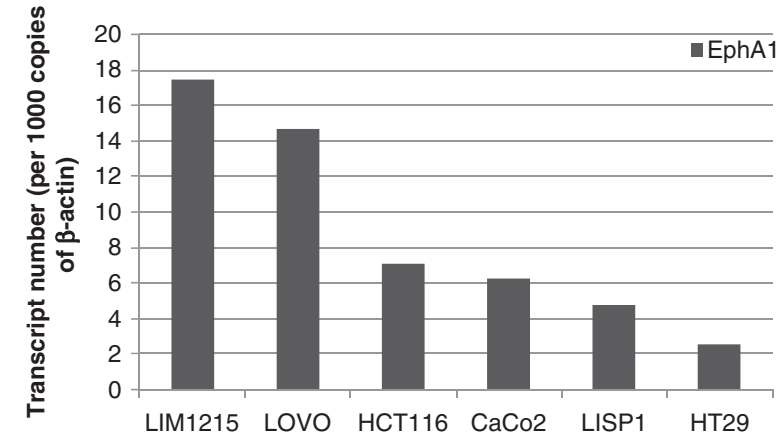

B

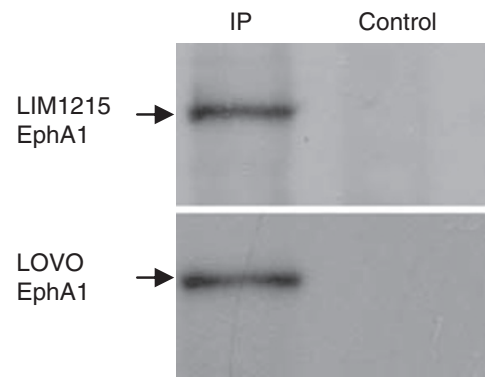

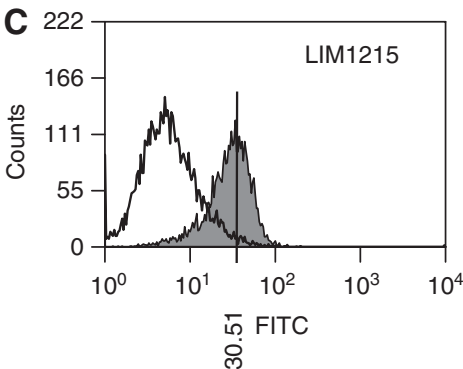
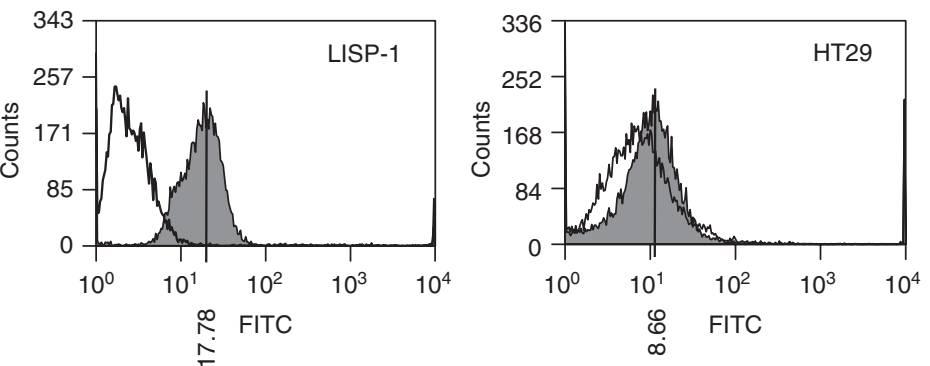

Figure I EphAI mRNA and protein expression in colorectal cancer (CRC) cell lines. (A) EphAI transcript levels normalised to I000 copies of $\beta$-actin quantitated by qPCR. (B) EphAI protein expression in LIMI2I5 and LOVO cell lines determined through immunoprecipitation followed by western blot analysis using an in-house rabbit anti-EphAI antibody. (C) EphAI protein levels determined by flow cytometry analysis. Fluorescence resulting from EphAI protein expression (shaded) is shown relative to the secondary-only control cells. The median fluorescence value is shown. 


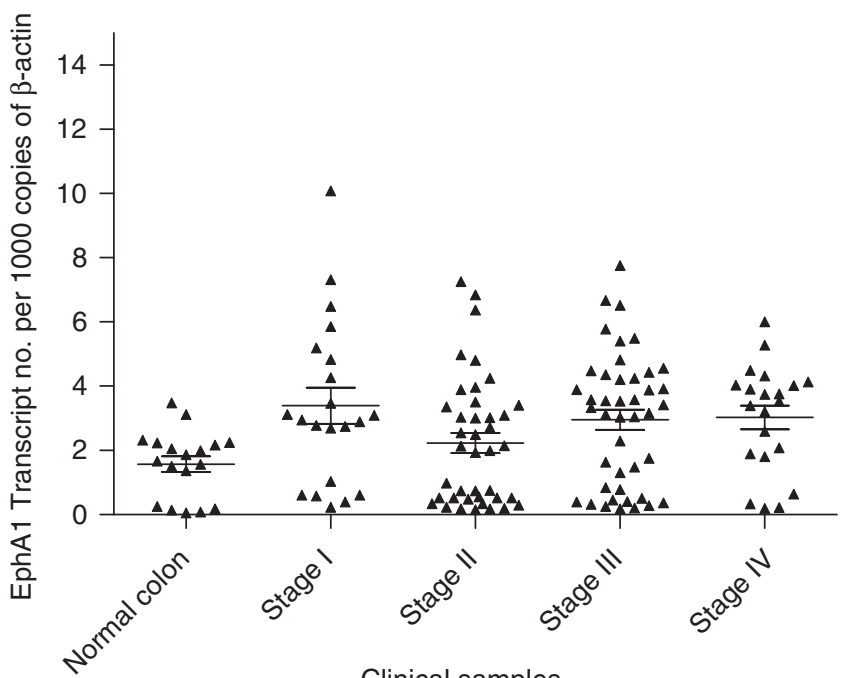

Clinical samples

Figure 2 EphAI mRNA expression in quantitative PCR (qPCR) colon tissue arrays. EphAI transcript levels normalised to I000 copies of $\beta$-actin. The horizontal bars represent the mean and the standard error of the mean.
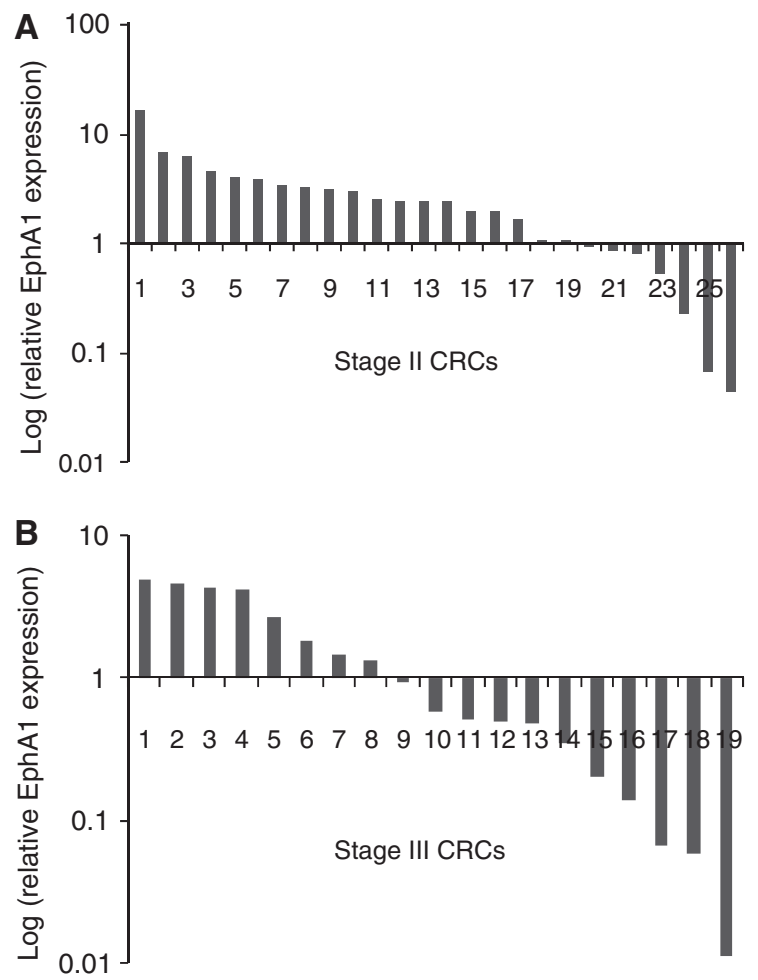

Figure 3 Gene expression level of EphAI in (A) stage II and (B) stage III colorectal cancer (CRC) samples. Expression is shown relative to its paired normal sample.

adjusting for age, gender and stage $(P=0.02, \mathrm{RR}=1.7,95 \%$ $\mathrm{CI}=1.0-2.8$ ) (Figure 4). EphA1 expression was independent of age, gender, tumour type and grade, although overall survival was marginally better in women compared to men $(P<0.05)$.

\section{Immunohistochemistry}

Immunohistochemistry for EphA1 was assessed in the $53 \mathrm{CRCs}$ and paired normal tissue. In normal colonic epithelium, stronger

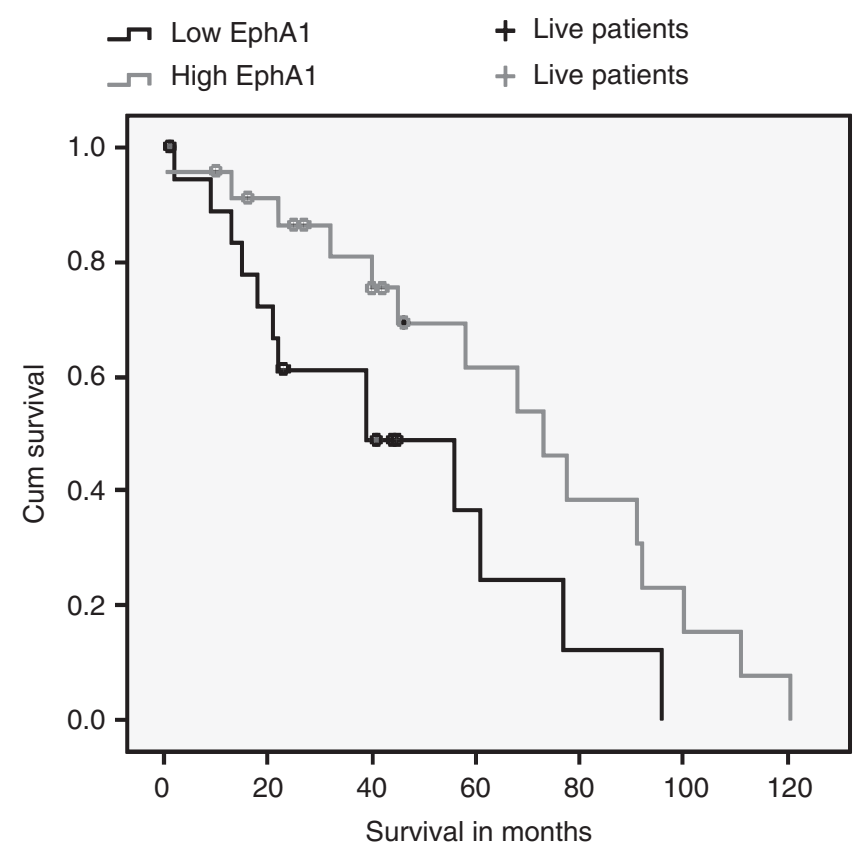

Figure 4 Unadjusted Kaplan-Meier survival curves from the date of diagnosis for patients with high $(\uparrow)$ and low $(\downarrow)$ levels of EphA I expression. Follow-up time, from the date of diagnosis to the date of last review for patients still living, is represented by the + symbol.

membrane staining was observed at the surface epithelium and was absent at the base of the crypt. In the corresponding CRCs, membrane EphA1 expression was observed with varying degrees of cytoplasmic expression (Supplementary Figure 1). Overall, immunohistochemistry data showed a good correlation with EphA1 mRNA expression in the clinical samples (Supplementary Table 3).

\section{EphA1 promoter methylation inversely correlates with EphA1 expression in CRC}

Although many reports (Hirai et al, 1987; Maru et al, 1990; Robinson et al, 1996; Kao et al, 2003) have shown upregulation of EphA1 in CRCs, and more recently downregulation, mechanisms of downregulation have not been examined (Hafner et al, 2006). In seeking a mechanism for EphA1 downregulation, epigenetic silencing due to methylation analysis of a CpG island in the EphA1 gene was investigated.

Analysis of the human EphA1 gene on the http://www.ebi.ac.uk/ emboss/cpgplot/ website using the accepted definition of a $\mathrm{CpG}$ island ( $\geqslant 200 \mathrm{bp}$ with a $\mathrm{C}+\mathrm{G}$ content $>50 \%$ and an observed CpG/expected CpG >0.6) (Gardiner-Garden and Frommer, 1987) was performed (Supplementary Figures 2 and 3). We identified a $251 \mathrm{bp} \mathrm{CpG}$ island starting $13 \mathrm{bp}$ downstream of the translation start site (A of the $\mathrm{ATG}=+1$ ) that spans exon 1 and intron 1 of the EphA1 gene and contained $22 \mathrm{CpG}$ sites (Figure 5). A $153 \mathrm{bp}$ CG-rich region immediately upstream of the translation start site, encompassing the $5^{\prime}$ UTR region and proximal promoter region, contained $14 \mathrm{CpG}$ sites but did not satisfy the criteria of a CpG island.

Initial screening of the $5^{\prime}$-CG-rich region through bisulfite sequencing revealed consistent methylation of $\mathrm{CpG}$ sites $12-14$ (Figure 5) in all CRC and corresponding normal samples. Methylation of these sites was present regardless of the level of EphA1 mRNA expression, suggesting that this region is not involved in gene regulation. However, this provided a useful 
Exon1
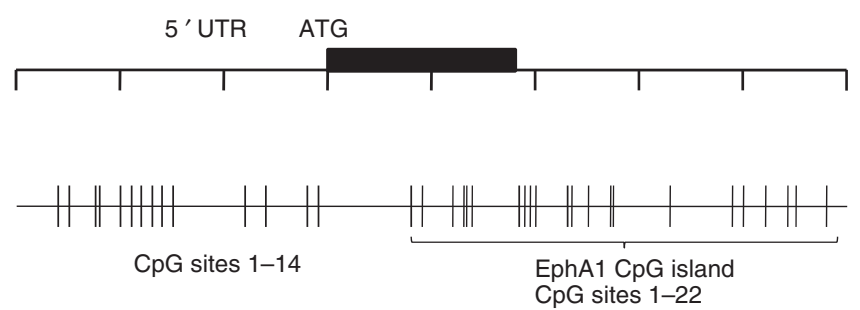

Figure 5 Genomic structure and localisation of the CpG regions of EphAI. The CpG sites are indicated by vertical bars. The methylation status of the 22 CpG sites within the CpG island and the 14 CpG sites located in the CpG-rich 5'-CG-rich region were assessed using bisulfite sequencing.

internal control for assessment of the effect of methylation on gene expression in this region.

Preliminary sequencing of the $\mathrm{CpG}$ island using bisulphitetreated DNA from 37 paired normal and CRC samples established that the average rate of methylation in these samples was $20.4 \%$. We employed melting profile analysis as a means to assay for methylation status. To establish a baseline, we used the CRC cell line LIM1215 expressing high levels of EphA1. Bisulfite sequencing of LIM1215 established that there was no detectable methylation of the EphA1 CpG island in this cell line. Conversely, when treated with Sss 1 methyltransferase, the EphA1 CpG island was completely methylated in this cell line. These samples were used as negative and positive controls in each run (Supplementary Figure 4A). Using a dilution series, it was established that the presence of greater than $20 \%$ methylation results in a shift of the curve (Supplementary Figure 4B). On the basis of the average rate of methylation observed through bisulfite sequencing data and melt curve analysis, we found that a case was considered methylated if the level of methylation was greater than $20 \%$ and unmethylated if the level was less than $20 \%$.

Methylation of EphA1 was observed in 26 out of 53 (49\%) of CRCs. Methylation was also detected in 15 cases of non-malignant colon tissue. No methylation was detected in 21 out of $53(40 \%)$ cases. In keeping with a function in silencing gene expression, methylation was more widespread in patients displaying downregulation of the gene $(P<0.01)$ (Supplementary Figure 5A). Intriguingly, methylation was significantly higher at the $3^{\prime}$ end of the $\mathrm{CpG}$ island (CpG sites 11-22) compared to the entire $\mathrm{CpG}$ island $(P<0.01)$ (Supplementary Figure $5 B)$. An inverse correlation was identified between overall methylation and EphA1 expression $(r=-0.3)$; however, the correlation coefficient was stronger when compared to the $3^{\prime}$ end of the CpG island $(r=-0.6)$. A strong positive correlation was also evident between increased EphA1 expression and the absence of methylation $(r=0.7)$.

Our studies did not attempt to elucidate whether loss of EphA1 expression was due to biallelic methylation or a combination of methylation and allelic loss. Further examination of bisulfite sequences of the few cases over-expressing EphA1 in the presence of methylation revealed that methylation was primarily present at the $5^{\prime}$ end of the CpG island and not the $3^{\prime}$ end of the island where methylation was primarily detected in low expressing CRCs.

\section{$5^{\prime}$-Aza-2'-deoxycytidine treatment and SBHA treatment of CRC cell lines}

Direct evidence that methylation influences EphA1 expression was obtained by demonstrating that $5^{\prime}$-aza- $2^{\prime}$-deoxycytidine treatment restored expression in HT29, and increased expression in LISP1 and HCT116 cells (Figure 6 - data shown for HT29). EphA1 mRNA expression, methylation status and protein expression were examined through qPCR, bisulfite sequencing and flow cytometry, respectively. Following $5^{\prime}$-aza-2'-deoxycytidine treatment, EphA1 underwent complete demethylation at $\mathrm{CpG}$ sites 1-22 (Figure 6A) and was accompanied by re-expression of the gene (Figure $6 \mathrm{~B}$ and C). Because methylated DNA binds methylcytosine binding proteins that in turn interact with $\mathrm{HDAC}$, the cells also were treated with the HDAC inhibitor, SBHA, in combination with the demethylating agent. Bisulfite sequencing revealed some aberrant demethylation in samples treated with SBHA alone (data not shown); however, this did not result in complete demethylation of the sample as with $5^{\prime}$-aza-2'-deoxycytidine. Combination treatment resulted in a further increase in gene expression; however, this was not significantly higher compared to the demethylating agent alone.

\section{DISCUSSION}

In this study we show that human CRC cell lines have variable levels of EphA1 expression. To validate the use of qPCR in tumour samples, we used these lines to show that mRNA expression correlated closely with protein expression (Figure 1A and B). When 125 CRC samples were compared with a set of 18 normal colon samples a significant increase in EphA1 expression was seen in the majority of CRC samples. However, all stages contained some samples with reduced expression compared with the normals. To make a more precise comparison of tumour with normal tissue, we obtained 53 paired normal and malignant CRCs cases. The heterogeneity of expression was confirmed in these samples with over half showing significantly increased expression compared with paired normal and most of the remainder showing significantly decreased expression compared to paired normal. As with cell lines, EphA1 mRNA levels correlated with protein levels as determined by immunohistochemistry. In seeking to understand this biphasic expression pattern, we found that reduced EphA1 expression was more frequent in late-stage CRCs (stage III $v s$ stage II), suggesting that there was a selective loss of expression during tumour progression. In support of this notion, patients with low EphA1 expressing tumours had significantly shorter survival than the high EphA1 group.

We had previously shown that reduced expression of EphA3 in haematological tumours was linked to promoter methylation (Dottori et al, 1999). As with EphA3, the EphA1 gene was shown to have a CpG island encompassing the $5^{\prime}$ end of the gene. We showed that the $\mathrm{CpG}$ island was significantly hypermethylated in low EphA1 expressing CRCs. Methylation of the $3^{\prime}$ end of the CpG island was even more significant. The re-expression of EphA1 upon treatment with a demethylation agent suggests that methylation has a regulatory function in EphA1 expression. Conservation of EphA1 across species raise the possibility that this $3^{\prime}$ region of the $\mathrm{CpG}$ island harbours key regulatory elements of the EphA1 gene. Notwithstanding contributions by other mechanisms, such as loss of heterozygosity, these data indicate that control of gene expression by methylation is a major mechanism of silencing of EphA1.

Our data show that EphA1 over-expression is commonly seen in locally invasive CRC but that downregulation is more frequent in metastatic CRC, in many cases mediated through epigenetic gene silencing. A similar phenomenon has been described for EphB2, where the loss of expression was associated with cancer progression (Batlle et al, 2005; Lugli et al, 2005; Guo et al, 2006), and higher EphB2 expression was associated with prolonged survival (Guo et al, 2006). More recently, EphB2 was reported to be inactivated through promoter hypermethylation in a subset of CRCs (Alazzouzi et al, 2005). EphB1 downregulation was also observed in pooled CRCs (Hafner et al, 2004). Similarly, there is emerging evidence to suggest that EphA RTK may also be downregulated in other malignancies. A recent study demonstrated significant downregulation of EphA1 in basal cell and squamous 
A

\begin{tabular}{|l|l|l|l|l|l|l|l|l|l|l|l|l|l|l|l|l|l|l|l|l|l|l|}
\hline $\begin{array}{l}\text { CpG } \\
\text { sites }\end{array}$ & 1 & 2 & 3 & 4 & 5 & 6 & 7 & 8 & 9 & 0 & 1 & 2 & 3 & 4 & 5 & 6 & 7 & 8 & 9 & 0 & 1 & 2 \\
\hline $\begin{array}{l}\text { Untreate } \\
\text { d }\end{array}$ & & & & & & & & & & & & & & & & & & & \\
\hline
\end{tabular}

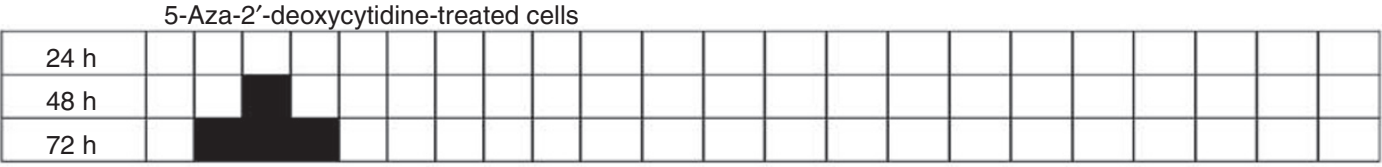

5-Aza-2'-deoxycytidine and Suberic bishydroxamate-treated cells

\begin{tabular}{|l|l|l|l|l|l|l|l|l|l|l|l|l|l|l|l|l|l|l|l|l|l|l|l|}
\hline $24 \mathrm{~h}$ & & & & & & & & & & & & & & & & & & & & & & \\
\hline $48 \mathrm{~h}$ & & & & & & & & & & & & & & & & & & & & & \\
\hline $72 \mathrm{~h}$ & & & & & & & & & & & & & & & & & & & & & & \\
\hline
\end{tabular}
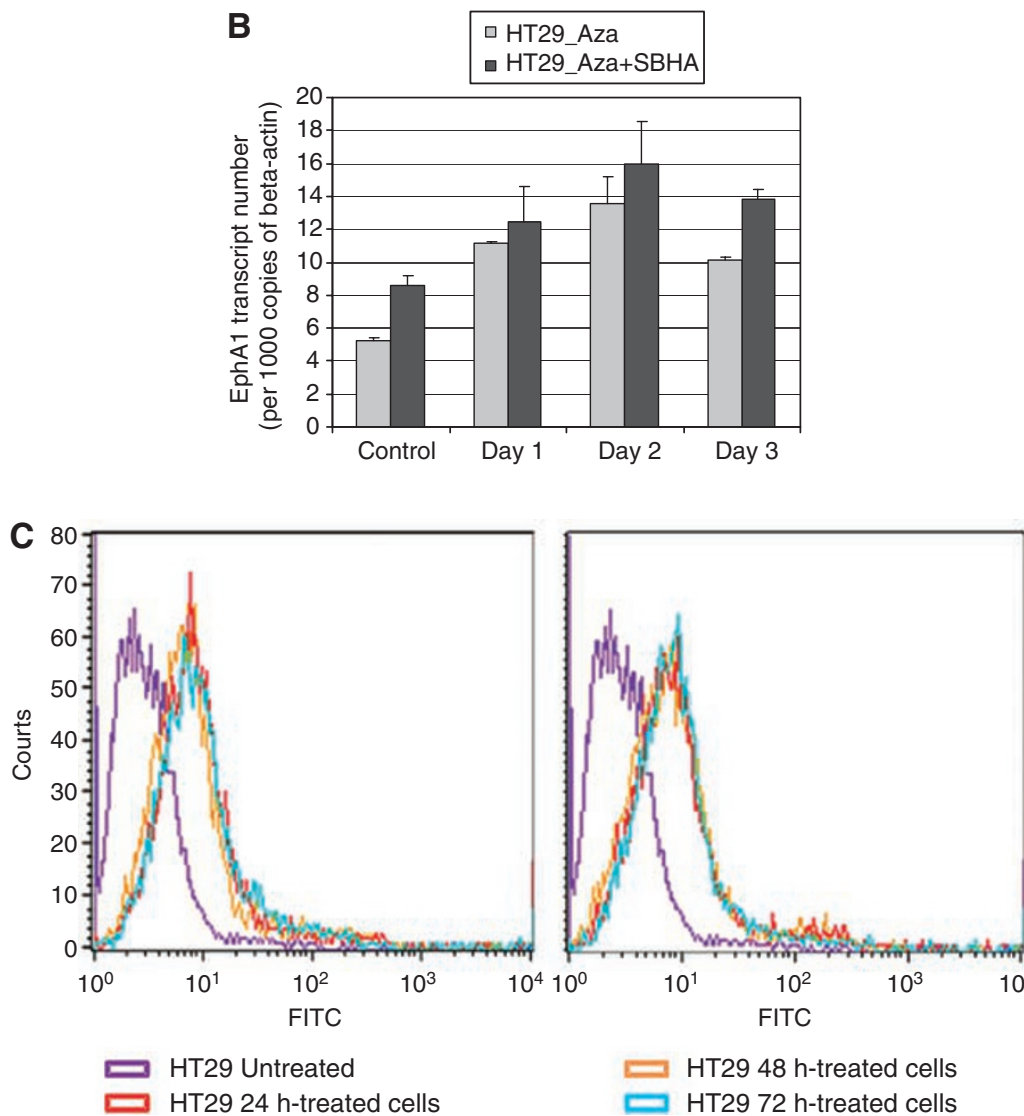

Figure 6 Correlation between methylation status and EphAI expression. HT29 cells were treated with 5'-aza-2'-deoxycytidine and histone deacetylase inhibitor (suberic bishydroxamate, SBHA) for 24, 48 and $72 \mathrm{~h}$. (A) Methylation status of the EphAI CpG island following treatment as verified by sequencing. (B) EphAI mRNA expression quantitated by real-time PCR following treatment. (C) EphAI protein levels determined by FACS analysis following treatment.

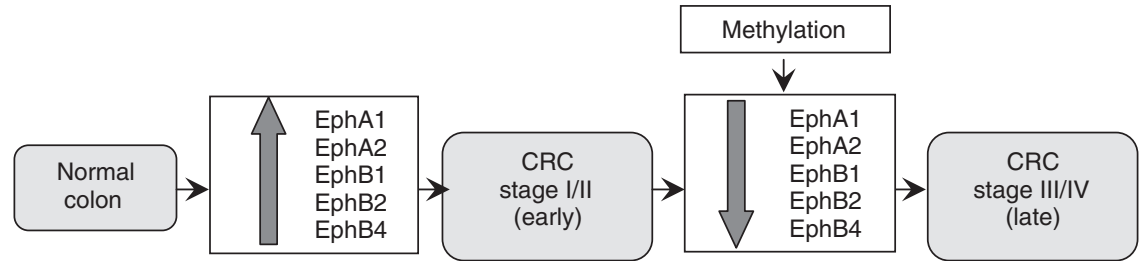

Figure 7 Pathway in colorectal cancer (CRC) progression from normal colon to late-stage cancer. 
cell carcinomas, through immunohistochemistry (Hafner et al, 2006). Kataoka et al (2004) demonstrated that EphA2 and ephrin A1 expression in CRC was associated with clinicopathological parameters. Both genes were significantly over-expressed in stages I and II; however, this was less apparent in stages III and IV, suggesting that loss of these genes is important in the progression of late-stage CRCs (Kataoka et al, 2004). Interestingly, decreased EphA7 and EphA6 expression has been reported in pooled CRCs compared to normal colon (Hafner et al, 2004). This finding was confirmed in CRCs where epigenetic silencing was shown to be associated with the downregulation of EphA7 (Wang et al, 2005).

An interesting observation emerging from these studies is the likely potential for these genes to have separate yet overlapping function in CRCs. Our data and other studies suggest that one or more of the Eph genes, in particular, EphA1, EphA2, EphB1, EphB2 and $E p h B 4$, are upregulated and may have an oncogenic function in the early stages of malignant transformation in the colon (Figure 7). Subsequent gene silencing through methylation and/or somatic genetic changes may be important in facilitating tumour migration/invasion. Given the direct correlation between loss of EphA1 expression and the progression of CRC to a more invasive phenotype, EphA1 appears to be a potentially valuable marker, particularly as part of algorithms for defining those patients with a poor prognosis.

Eph proteins have been identified as therapeutic targets in cancer, both as anti-cancer and anti-angiogenic agents. Several

\section{REFERENCES}

Adams RH (2002) Vascular patterning by Eph receptor tyrosine kinases and ephrins. Sem Cell Dev Biol 13: 55-60

Alazzouzi H, Davalos V, Kokko A, Domingo E, Woerner SM, Wilson AJ, Konrad L, Laiho P, Espin E, Armengol M, Imai K, Yamamoto H, Mariadason JM, Gebert JF, Aaltonen LA, Schwartz S, Arango D (2005) Mechanisms of inactivation of the receptor tyrosine kinase EPHB2 in colorectal tumors. Cancer Res 65: 10170-10173

Batlle E, Bacani J, Begthel H, Jonkheer S, Gregorieff A, van de Born M, Malats N, Sancho E, Boon E, Pawson T, Gallinger S, Pals S, Clevers H (2005) EphB receptor activity suppresses colorectal cancer progression. Nature 435: 1126 - 1130

Batlle E, Henderson JT, Beghtel H, van de Born MM, Sancho E, Huls G, Meeldjik J, Robertson J, van de Wetering M, Pawson T, Clevers H (2002) Beta-catenin and TCF mediate cell positioning in the intestinal epithelium by controlling the expression of EphB/ephrinB. Cell 111: 251-263

Berclaz G, Flutsch B, Altermatt HJ, Rohrbach V, Djonov V, Ziemiecki A, Dreher E, Andrew AC (2002) Loss of EphB4 receptor tyrosine kinase protein expression during carcinogenesis of the human breast. Oncol Rep 9: $985-989$

Brantley-Sieders D, Schmidt S, Parker M, Chen J (2004) Eph receptor tyrosine kinases in tumor and tumor microenvironment. Curr Pharm Des 10: $3431-3442$

Boyd AW, Lackmann M (2001) Signals from Eph and ephrin proteins: a developmental tool kit. Sci STKE 200: RE20-RE26

Coulthard MG, Lickliter JD, Subanesan N, Chen K, Webb GC, Lowry AJ, Koblar S, Bottema CD, Boyd AW (2001) Characterization of the Epha1 receptor tyrosine kinase: expression in epithelial tissues. Growth Factors 18: $303-317$

Dodelet VC, Pasquale EB (2000) Eph receptors and ephrin ligands: embryogenesis to tumorigenesis. Oncogene 19: 5614-5619

Dottori M, Down M, Huettmann A, Fitzpatrick DR, Boyd AW (1999) DNA methylation regulates expression in hematopoietic tumor cells. Blood 94: $2477-2486$

Gale NW, Holland SJ, Valenzuela DM, Flenniken A, Pan L, Ryan TE, Henkemeyer M, Strebhardt K, Hirai H, Wilkinson DG, Pawson T, Davis S, Yancopoulos GD (1996) Eph receptors and ligands comprise two major specificity subclasses and are reciprocally compartmentalized during embryogenesis. Neuron 17: 9-19

Gardiner-Garden M, Frommer M (1987) CpG islands in vertebrate genomes. J Mol Biol 196: 261-282 therapeutic candidates including antibodies to EphA2 (Landen et al, 2005), EphA3 (Vearing et al, 2005) and EphB2 (Mao et al, 2004) are in advanced pre-clinical or early clinical assessment. Although therapies targeting the high EphA1 expression in early phase CRC seem logical, the loss of expression in advanced disease poses the risk that targeted therapies may select for loss of expression and thus contribute to disease progression. Recognising the surprising biphasic pattern of EphA1 expression during CRC progression, and potentially in other epithelial tumours, requires a careful evaluation of the function of Eph expression in CRC and their rational targeting with Eph-specific therapies.

\section{ACKNOWLEDGEMENTS}

This study was supported by grants from the National Health and Medical Research Council, the Leukaemia Foundation of Queensland, Queensland Cancer Fund and the Royal Brisbane Hospital Research Foundation. We thank Dr Brett Stringer for useful discussion and assistance in reviewing the article and Professor David Gotley for provision of samples from the Princess Alexandra Hospital tumour tissue bank.

Supplementary Information accompanies the paper on British Journal of Cancer website (http://www.nature.com/bjc)
Guo DL, Zhang J, Yuen ST, Tsui WY, Chan AS, Ho C, Ji J, Leung SY, Chen X (2006) Reduced expression of EphB2 that parallels invasion and metastasis in colorectal tumors. Carcinogenesis 27: 454-464

Hafner C, Becker B, Landthaler M, Vogt T (2006) Expression profile of Eph receptors and ephrin ligands in human skin and downregulation of EphA1 in nonmelanoma skin cancer. Mod Pathol 19: 1369-1377

Hafner C, Schmitz G, Meyer S, Bataille F, Hau P, Langmann T, Dietmaier W, Landthaler M, Vogt T (2004) Differential gene expression of Eph receptors and Ephrins in benign human tissues and cancers. Clin Chem 50: $490-499$

Hirai H, Maru Y, Hagiwara K, Nishida J, Takaku F (1987) A novel putative tyrosine kinase receptor encoded by the eph gene. Science 238: $1717-1720$

Kao HW, Chen HC, Wu CW, Lin WC (2003) Tyrosine-kinase expression profiles in human gastric cancer cell lines and their modulations with retinoic acids. $B r J$ Cancer 88: $1058-1064$

Kataoka H, Igarashi H, Kanamori M, Ihara M, Wang JD, Li ZY, Shimamura T, Kobayashi T, Maruyama K, Nakamura T, Arai H, Kajimura M, Hanai H, Tanaka M, Sugimura H (2004) Correlation of EPHA2 overexpression with high microvessel count in human primary colorectal cancer. Cancer Sci 95: $136-141$

Kataoka H, Tanaka M, Kanamori M, Yoshii S, Ihara M, Wang YJ, Song JP, Li ZY, Arai H, Otsuki Y, Kobayashi T, Konno H, Hanai H, Sugimura H (2002) Expression profile of EFNB1, EFNB2, two ligands of EPHB2 in human gastric cancer. J Cancer Res Clin Oncol 128: $343-348$

Landen CN, Kinch MS, Sood AK (2005) EphA2 as a target for ovarian cancer therapy. Expert Opin Ther Targets 9: 1179-1187

Liu W, Ahmad SA, Jung YD, Reinmuth N, Fan F, Bucana CD, Ellis LM (2002) Coexpression of ephrin-Bs and their receptors in colon carcinoma. Cancer 94: 934-939

Liu W, Jung YD, Ahmad SA, McCarthy MF, Stoeltzing O, Reinmuth N, Fan F, Ellis LM (2004) Effects of over expression of ephrin-B2 on tumor growth in human colorectal cancer. $\mathrm{Br} J$ Cancer 90: $1620-1626$

Lugli A, Spichtin H, Maurer R, Mirlacher M, Kiefer J, Huusko P, Azorsa D, Terracciano L, Sauter G, Kallioniemi OP, Mousses S, Tornillo L (2005) EphB2 expression across 138 human tumor types in a tissue microarray: high levels of expression in gastrointestinal cancers. Clin Cancer Res 11: $6450-6458$ 
Mao W, Luis E, Ross S, Silva J, Tan C, Crowley C, Chui C, Franz G, Senter P, Koeppen H, Polakis P (2004) EphB2 as a therapeutic antibody drug target for the treatment of colorectal cancer. Cancer Res 64: 781-788

Maru Y, Hirai H, Takaku F (1990) Overexpression confers an oncogenic potential upon the eph gene. Oncogene 5: 445-447

Nakamoto M, Bergemann AD (2002) Diverse roles for the Eph family of receptor tyrosine kinases in carcinogenesis. Microsc Res Tech 59: 58-67

Robinson D, He F, Pretlow T, Kung HJ (1996) A tyrosine kinase profile of prostate carcinoma. Proc Natl Acad Sci USA 93: 5958-5962

Saito T, Masuda N, Miyazaki T, Kanoh K, Suzuki H, Shimura T, Asao T, Kuwano H (2004) Expression of EphA2 and E-cadherin in colorectal cancer: correlation with cancer metastasis. Oncol Rep 11: 605-611

Sancho E, Batlle E, Clevers H, Sawai Y, Tamura S, Fukui K, Ito N, Imanaka K, Saeki A, Sakuda S, Kiso S, Matsuzawa Y, Hafner C, Bataille F, Meyer S, Becker B, Roesch AL, Landthaler M, Vogt T (2003) Live and let die in the intestinal epithelium. Curr Opin Cell Biol 15: $763-770$
Stephenson SA, Slomka S, Douglas EL, Hewett PJ, Hardingham JE (2001) Receptor protein tyrosine kinase EphB4 is up-regulated in colon cancer. BMC Mol Biol 2: 15

Vearing C, Lee FT, Wimmer-Kleikamp S, Spirkoska V, To C, Stylianou C, Spanevello M, Brechbiel M, Boyd A, Scott AM, Lackmann M (2005) Concurrent binding of anti-EphA3 antibody and ephrin A5 amplifies EphA3 signalling and downstream responses: potential as EphA3-specific tumor targeting reagents. Cancer Res 65: 6745-6754

Wang J, Kataoka H, Suzuki M, Sato N, Nakamura R, Tao H, Maruyama K, Isogaki J, Kanaoka S, Ihara M, Tanaka M, Kanamori M, Nakamura T, Shinmura K, Sugimura H (2005) Down regulation of EphA7 by hypermethylation in colorectal cancer. Oncogene 24: 5637-5647

Wilkinson DG (2003) How attraction turns to repulsion. Nat Cell Biol 5: $851-853$

Worm J, Aggerholm A, Guldberg P (2001) In-tube DNA methylation profiling by fluorescence melting curve analysis. Clin Chem 47: $1183-1189$ 